\title{
Transformer-Less Series Voltage Sag Compensator without Energy Storage Capacitor for Three-Phase Three-Line Systems
}

\author{
Zenglu Chen Non-member (Xi'an Jiaotong University, chen_zenglu@ hotmail.com, \\ Xi' an University of Engineering Science and Technology) \\ Toshifimi Ise Member (Osaka University, ise@eei.eng.osaka-u.ac.jp)
}

Keywords: voltage sags, series compensation, transformer-less, energy storage capacitor-less, tracing control, double delta modulation

Voltage sags have become one of the most important power quality concerns in recent years. A series type of dynamic sag corrector (named DySC) was proposed by Brumsickle etc. The DySC units have been shown to be smaller in size and lower cost. But in this scheme the neutral of power supplies is necessary, so a socalled Zig-Zag transformer is used to recreate the power neutral for a three-phase three-line system.

In this paper, a new scheme is proposed as shown in Fig. 1. The capacitors of the inverter in every phase are charged by two line-toline voltages instead of one line-to-neutral voltage as in the DySC. So the neutral in main circuit is not necessary. When voltage sags occur, the inverters operate; controlling the bypass currents down to zero and then turning off the bypass switchs; the inverters supply the missing voltage and help to maintain rated voltage at the terminals of the critical load. During compensation, the inverter continuously draw power from the incoming source lines, so the capacitors in the inverters can be much smaller than other voltage compensators such as DVR, and it can compensate deeper sags than DySC espetically down to zero, because the inverters are charged by line-to-line voltages instead of line-to-neutral. In fact, the capacitors in the inverters of proposed scheme are not energy storers but filters, and there is no limit on their compensating time interval.

Theoretical analysis show that the proposed scheme can compensate symmetrical three-phase voltage sags down to $37 \%$ of the normal voltages continuously, and compensate one or two phases sags

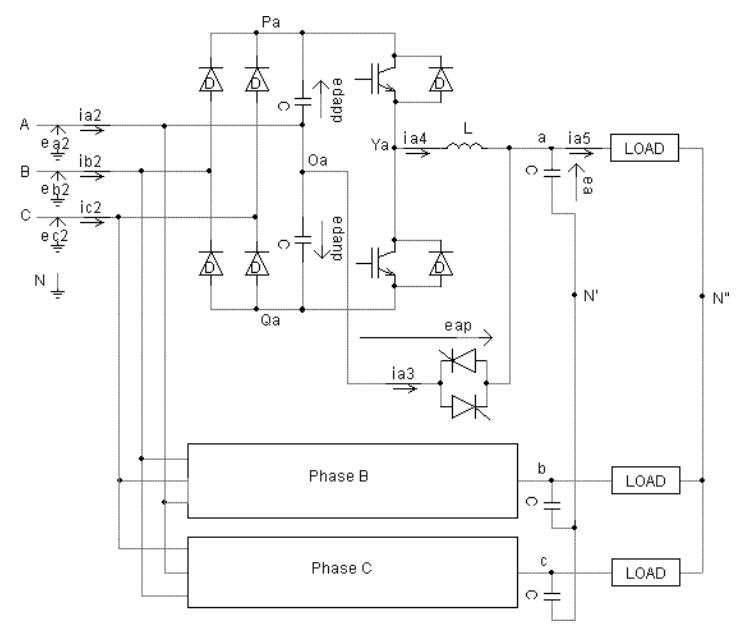

Fig. 1. Proposed scheme down to zero continuously if at least one phase voltage is maintained normal. A tracking control method named as "double $\delta$ modulation" is used. "Double $\delta$ modulation" means the combination of tracing error comparison and carrier timing. The inverters are controlled by the SPWM signals, of which the timer synchronizes the falling edges and the comparators decides the rising edges. Both the comparator and the timer together determine tracking precision. Especially the timer ensures constant switching frequency.

A current slope automatic control method is used for the bypass switch's commutation in this system. When voltage sag occurs the currents flowing in the bypass switches will be controlled down to zero in designated (positive or negative) constant slopes, and then they are turned off.

One of simulation results in this paper is shown in Fig. 2, where the upper waveforms are the sagged incoming source side line-toline voltages, the middle waveforms are the load side line-to-line voltages after compensation, and the lower waveforms are the DC bus voltages of the inverter in phase-A. From the figures we can see excellent compensation characteristics. Compensation time is not limited, because the DC bus voltages is almost constant after $\mathrm{t}=0.250 \mathrm{~s}$.

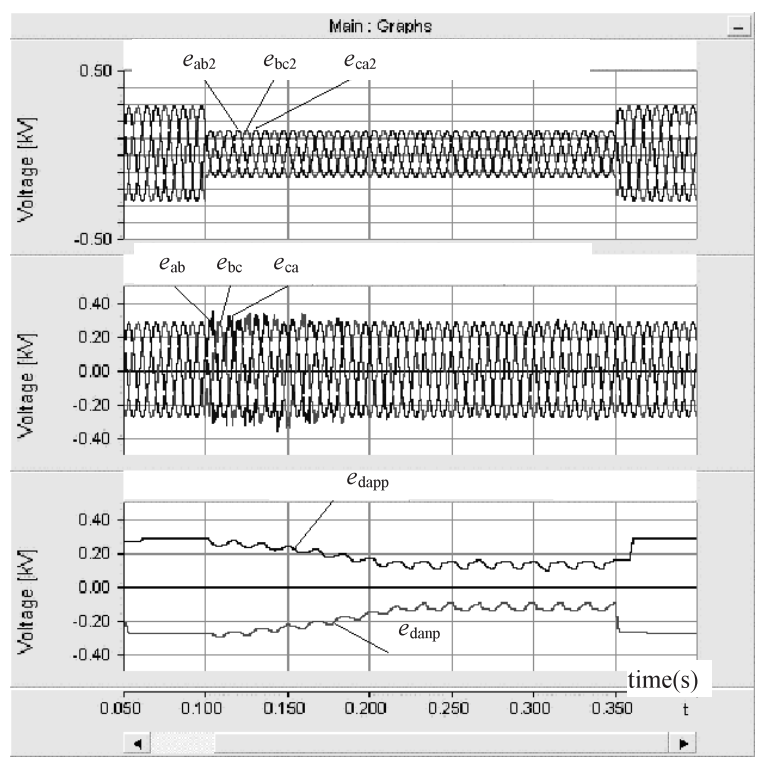

Fig. 2. System simulation result in symmetrical sags down to $44 \%$ residual 


\title{
Transformer-Less Series Voltage Sag Compensator without Energy Storage Capacitor for Three-Phase Three-Line Systems
}

\author{
Zenglu Chen* Non-member \\ Toshifumi Ise ${ }^{* *}$ Member
}

\begin{abstract}
A novel main circuit topology of transformer-less series voltage sag compensator is proposed. The sagged voltages are compensated by half bridge inverters, which are directly connected in series with the residual voltages and are charged by the residual line-to-line voltages. The proposed compensator can compensate symmetrical three-phase sags down to $37 \%$, or one or two phase sags down to zero if at least one phase is rated voltage. Besides the excellent compensation property related to the compensating depth, the proposed system only need small capacitance in the inverters because they are continuously charged by the residual voltages during the sags. In fact the capacitors are not energy storers but filters, so there is no limit on their compensating time interval. Theoretical analysis is done and the concerned results are derived. Simulation results on resistance loads demonstrated the compensating performances.
\end{abstract}

Keywords: voltage sags, series compensation, transformer-less, energy storage capacitor-less, tracing control, double delta modulation

\section{Introduction}

Voltage sags have become one of the most important power quality concerns in recent years. These power quality events typically last for less than $1 \mathrm{~s}$. Following on the increasing application of sensitive electronic equipments, such as computers, automation control devices, communication systems, etc, the voltage sags have become a serious problem. These sensitive loads can be easily interrupted by voltage sags and the resulted losses are significant ${ }^{(1)(2)}$.

A number of approaches already exist to compensate for this problem. There are mainly two types of voltage sag compensators, series type or parallel type. Series injection sag compensators offer the advantage of only having to compensate for the decrease in supply voltage during voltage sag. This results in a significant reduction in the converter ratings and energy storage requirements. One of the series injection voltage sag compensators is dynamic voltage regulator (DVR), it offers the advantages of all of the series voltage sag compensators have, but the necessity for costly injection transformers is the major disadvantage of the transformerbased topologies ${ }^{(3)}$. A new series scheme for voltage sag compensation was proposed by Aeloiza etc ${ }^{(4)}$. In the scheme, a PWM ac-ac converter is employed in each phase, and an autotransformer is necessary. An independent winding of the autotransformer supplies power to the ac-ac converter, and the output of the converter is series with the incoming source to compensate the voltage sag. The autotransformer can be

\footnotetext{
* School of Electrical Engineering, Xi'an Jiaotong University, China (Doctor student); School of Electronics and information Engineering, Xi' an Polytechnic University, China (Professor); Department of Electrical, Electronic and Information Engineering, Graduate School of Engineering, Osaka University (Foreign Researcher). 19, South Jinhua Rd, Xi'an, Shanxi, 710048, China.

** Department of Electrical, Electronic and Information Engineering,

Graduate School of Engineering, Osaka University

2-1, Yamada-oka Suita, Osaka 565-0871, Japan.
}

rated only for voltage sags, so the required size is smaller.

Another series type of dynamic sag corrector (named DySC) was proposed by W.E. Brumsickle etc ${ }^{(5)}$. The basic topology is shown as Fig. 1. A single-phase half bridge PWM inverter is connected in series with the incoming phase source and the load, in which the connecting point of two series capacitors is connected to the high voltage side of power source line, the connecting point of two series diodes is connected to the neutral and the connecting point of two series IGBTs is connected to load. Three phases are independent each other. In normal operation the phase-to-neutral voltage charge the capacitors of the inverter, a bypass switch composed of two anti-paralleled thyristors is conducting to supply the load. An inductor is connected in series with the inverter-bypass loop to prevent it from short circuit when commutation, and the inductor is a part of the output filter too. When voltage sags are happened, the bypass switch is opened first, and then the inverter operates and the output ac voltage is added to the residual voltage to restore it to normal. This allows it to correct for deep voltage sags down to $50 \%$ for a long time or down to zero for a short time. The DySC units have been shown to be smaller in size and lower in cost. But in this scheme the neutral of power supplies is necessary, so it cannot be used in

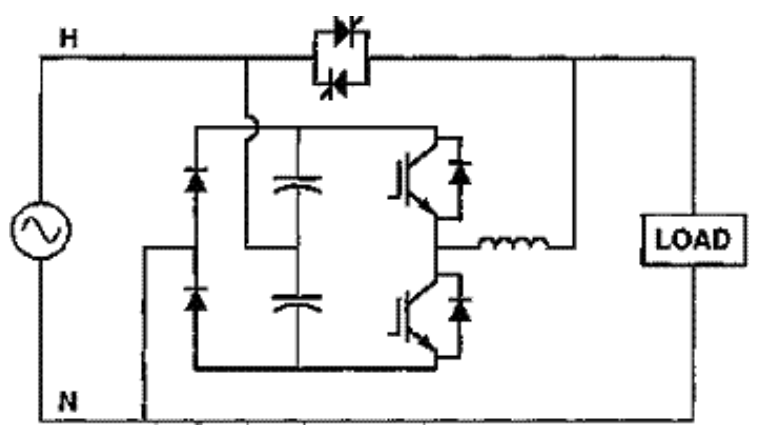

Fig. 1. Single-phase DySC topology ${ }^{(5)}$ 
three-phase three-line systems. Afterwards A. Bhadkamkar, etc proposed a new scheme for three-phase three-line systems ${ }^{(6)}$. A so-called Zig-Zag transformer is used to recreate the power neutral that is necessary to charge the three single phase inverters and to use as the reference of controller.

In this paper, a new main circuit topology is proposed in section 2 . Then the principle and basic properties of the new scheme are analyzed in section 3 . Section 4 shows the simulation results by using PSCAD software. Finally, section 5 concludes the paper.

\section{Proposed Scheme}

The proposed topology is shown in Fig. 2. Only phase-A is shown in detail and the phase- $\mathrm{B}$ and phase- $\mathrm{C}$ are symmetrical with phase-A. A half bridge inverter is used in series connection with the incoming source side line of phase-A. The source side line is connected to the connecting point of the two series capacitors; the load is connected to the connecting point of two series IGBTs. Other source side lines of phase- $\mathrm{B}$ and phase- $\mathrm{C}$ are connected to the connecting points of two series diode leg-couples, respectively. It is obvious that the capacitors in the inverter are charged by two line-toline voltages instead of one line-to-neutral voltage. So the neutral in main circuit is not necessary. A bypass switch is as the same as in Fig. 1.

During the normal voltages the bypass switches are closed, delivering utility power directly to the load; this can cancel the power loss in IGBTs and the filtering inductors. When voltage sags occur, the inverters operate; controlling the bypass currents down to zero and then turning off the bypass switches; the inverters supply the missing voltage and help to maintain rated voltage at the terminals of the critical load. During voltage sags, the incoming source lines can continuously supply the capacitors if necessary, so the capacitors in the inverters can be much smaller than other voltage compensators such as DVR, in which the compensating energy is only supplied by energy storage devices. Further more the proposed scheme can compensate symmetrical three-phase voltage sags down to $37 \%$ of the normal voltages continuously, and compensate one or two-phase voltage sags down to zero continuously if at least one phase voltage is maintained

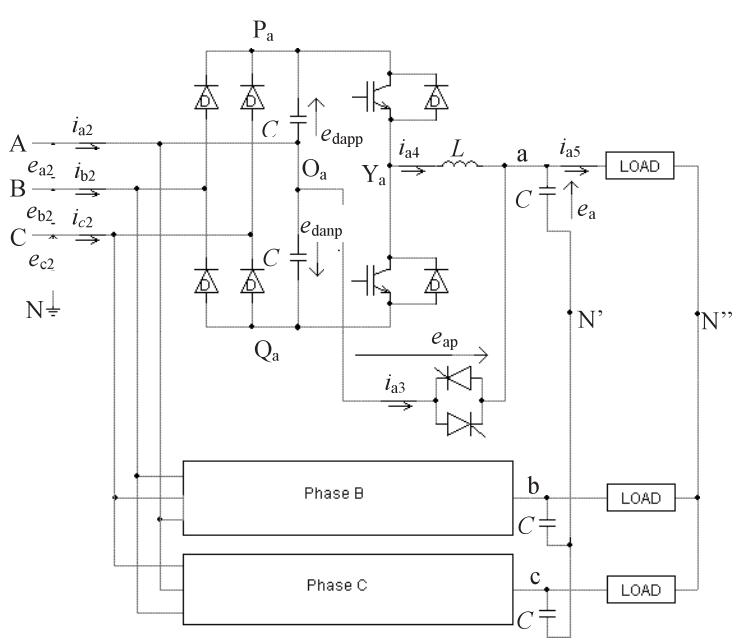

Fig. 2. Proposed scheme normal, because the inverters are operated by line-to-line voltages instead of line-to-neutral. The capacitors in the inverters of the proposed scheme are not energy storers but filters, and there is no limit on their compensating time interval.

\section{Analysis and Design}

In this section, the basic waveforms of the proposed main circuit topology are analyzed first. Then the theoretical result about the maximum compensated voltage sag depth is presented. Thirdly the control strategy used in this compensating system is shown. Finally, the bypass switches control method is discussed.

3.1 Basic Waveforms The basic waveforms of the proposed main circuit topology are shown in Fig. 3. Fig. 3(a) is the incoming three phase source voltages; denoted as $e_{\mathrm{a} 2}$, $e_{\mathrm{b} 2}$, and $e_{\mathrm{c} 2}$; they are sagged by $50 \%$ in the time interval from $0.1 \mathrm{~s}$ to $0.26 \mathrm{~s}$. Fig. 3(b) is a set of waveforms concerning the inverter in phase-A, where the connecting point of two capacitors, denoted as $\mathrm{O}_{a}$ in Fig. 2, that is the incoming source side line of phase-A is used as reference. Fig. 3(b) includes $e_{\text {dapp }}$ and $e_{\text {danp }}$ being the two DC bus voltages as shown in

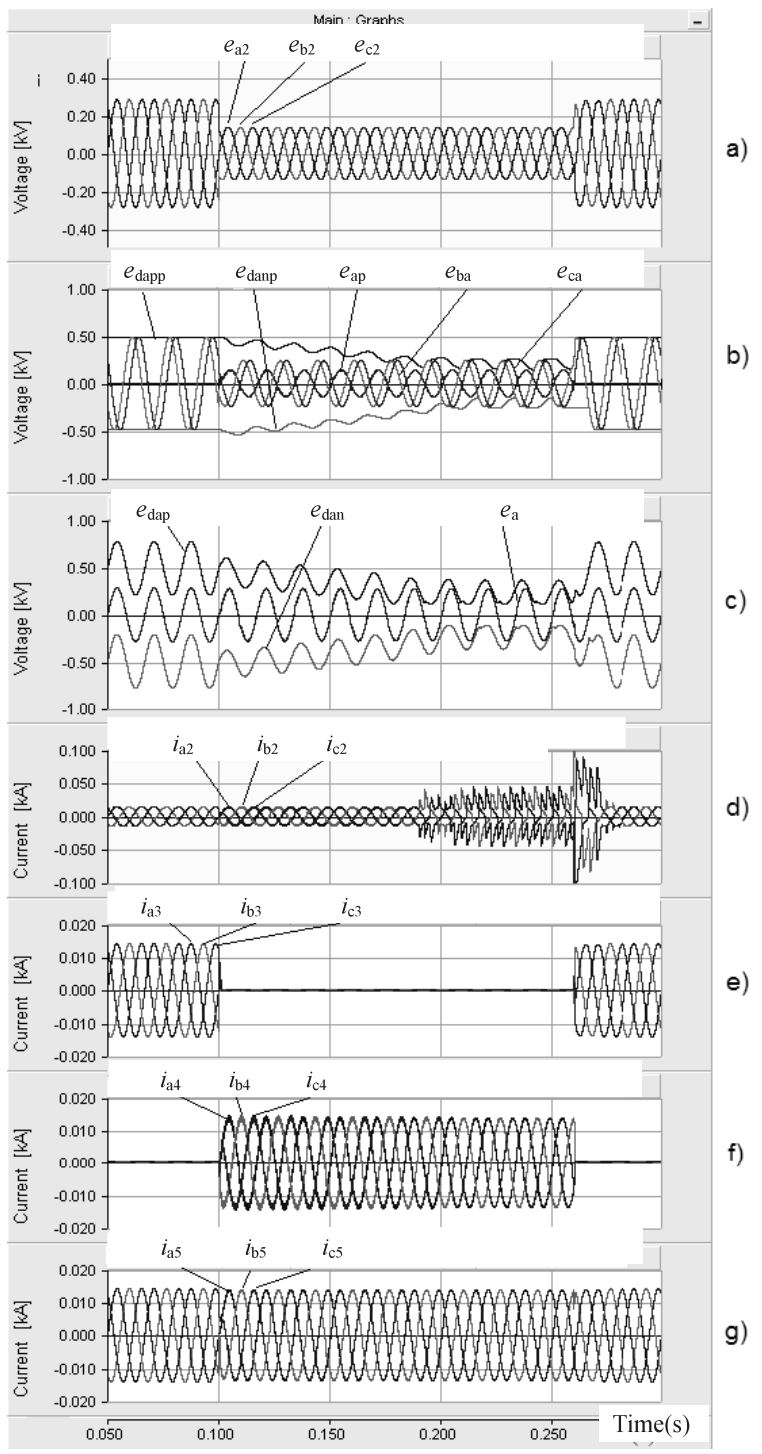

Fig. 3. The basic waveform of the main circuit 
Fig. 2, $e_{\text {ap }}$ being the inverter output to compensate the missing source voltage, $e_{\mathrm{ba}}$ and $e_{\mathrm{ca}}$ being the two line-to-line voltages charging the inverter. Fig. 3(c) is a set of waveforms, where $e_{\text {dap }}$ is the voltage between points $\mathrm{P}_{\mathrm{a}}$ (the positive DC bus) and $\mathrm{N}, e_{\mathrm{dan}}$ is the voltage between points $\mathrm{Q}_{a}$ (the negative $\mathrm{DC}$ bus) and $\mathrm{N}$, and $e_{a}$ is the final phase-a-to-N' output voltage. It is obvious that $e_{\mathrm{dap}} / e_{\mathrm{dan}} / e_{\mathrm{a}}$ are the sum of $e_{\text {dapp }} / e_{\text {danp }} / e_{\text {ap }}$ and the incoming residual source voltage $e_{\mathrm{a} 2}$, respectively. Fig. 3(d) is the incoming source currents denoted as $i_{\mathrm{a} 2}, i_{\mathrm{b} 2}$ and $i_{\mathrm{c} 2}$. Fig. 3(e) is the currents in the bypass switches denoted as $i_{\mathrm{a} 3}, i_{\mathrm{b} 3}$ and $i_{\mathrm{c} 3}$. Fig. 3(f) is the currents through inverters denoted as $i_{\mathrm{a} 4}, i_{\mathrm{b} 4}$ and $i_{\mathrm{c} 4}$. Fig. $3(\mathrm{~g})$ is the load currents denoted as $i_{\mathrm{a} 5}, i_{\mathrm{b} 5}$ and $i_{\mathrm{c} 5}$. All of the symbols used in Fig. 3 are shown in Fig. 2.

During the time interval of constant normal source voltages, the DC voltages of capacitors, $e_{\text {dapp }}$ and $e_{\text {danp }}$, are maintained constant and the incoming current are equal to load, that is $i_{j 2}=i_{j 5}$, where $j=\mathrm{a}, \mathrm{b}, \mathrm{c}$. As soon as a voltage sag occurs, the inverters start operation to compensate the missing load voltage to normal after shutting down of bypass switches. In the first period of voltage sags, from $0.1 \mathrm{~s}$ to $0.19 \mathrm{~s}$, the inverters are operated by the stored energy of capacitors, while the DC voltage amplitude in capacitors maintain always larger than the amplitude of the residual line-toline $\mathrm{AC}$ voltages as shown in Fig. 3(b). In this duration, the source currents still maintain equal to the load currents as shown in Fig. 3(d). The capacitor voltages are decreased due to the compensation of voltage sag. While the amplitude of the residual line-to-line AC voltages is larger than the voltage of DC capacitors as shown in the period from $0.19 \mathrm{~s}$ to $0.26 \mathrm{~s}$, the inverters are operated to restore the missing voltage due to voltage sag, and the DC capacitors are charged by the line-toline voltages, for example $e_{\mathrm{ba}}$ and $e_{\mathrm{ca}}$ in phase-a, to keep the voltages of DC capacitors in dynatical balance, which results in larger and undulating source currents than the load currents as shown in Fig. 3(d). When the voltage sags are canceled, at $0.26 \mathrm{~s}$ in Fig. 3 , the inverters are shut down and the bypass switches are in operation again, at which the source currents, $i_{\mathrm{a} 2}, i_{\mathrm{b} 2}$ and $i_{\mathrm{c} 2}$, increase suddenly to charge the capacitors to higher voltages.

3.2 The Maximum Compensated Depth of the Sags A phasor map is shown in Fig. 4 in the case of voltage sags, where $i, j, k=A, B, C$, but $i \neq j \neq k$. Assume $i$ is the minimum one of the sagged three phase voltages, and $j$ is the maximum one of them. $e_{i 2}, e_{j 2}, e_{k 2}$ are the sagged incoming three phase voltages, $e_{i j 2}$ is the sagged line-to-line voltage between phase- $i$ and phase- $j$ which charges the inverter's capacitors in phase- $i$, where $e_{i R}$ is the rated voltage in phase- $i$, and $N$ is the theoretical neutral. Assume $p_{i}, p_{j}$ and $p_{k}$ are the sagging factors of phase $i, j$ and $k$ respectively, we have

$$
\left.\begin{array}{l}
e_{i 2}=p_{i} e_{i R} \\
e_{j 2}=p_{j} e_{j R} \\
e_{k 2}=p_{k} e_{k R}
\end{array}\right\}
$$

From the figure,

$$
e_{i j 2}=\sqrt{\left(e_{j 2} \cos \frac{\pi}{6}\right)^{2}+\left(e_{j 2} \sin \frac{\pi}{6}+e_{i 2}\right)^{2}} \ldots \ldots \ldots
$$

Further more, take the capacitor voltage ripples into consideration, because the capacitance of the capacitors in the

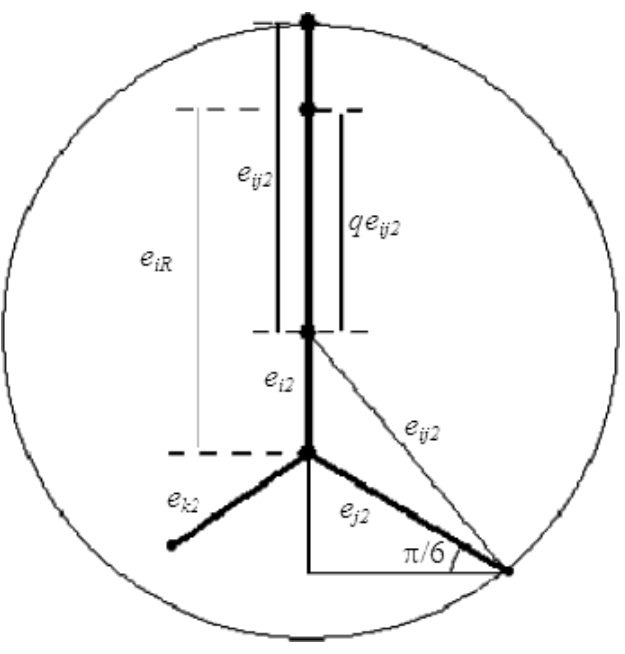

Fig. 4. Phasor map of the sagged voltages and its compensation

inverter need not be very large. When the energy in the capacitors consumed enough, the incoming sources begin to charge the capacitors and their voltages will maintain dynamical balance as shown in Fig. 3(b) during time interval about from $0.19 \mathrm{~s}$ to $0.26 \mathrm{~s}$. Let $q \in(0,1)$ a factor of filtering that denote the fluctuant degree of the voltage in the capacitors. $q$ is defined as the minimum ratio of the minimum voltage to the maximum voltage in the capacitors during the just said dynamic balance condition. We can obtain an approximate relation as following equation (3), and as shown in Fig. 4.

$$
e_{i R}=e_{i 2}+q e_{i j 2}
$$

Solve the equations of (1), (2), (3), and consider $e_{i R}=$ $e_{j R}=e_{k R}$, following result can be derived

$$
\frac{p_{i}^{2}-2 p_{i}+1}{p_{i}^{2}+p_{i} p_{j}+p_{j}^{2}}=q^{2}
$$

which is the relation of the allowable minimum and maximum sagging factors and the filtering factor under which the sags can be compensated.

If the capacitances are large enough; i.e. $q \cong 1$; equation (4) becomes

$$
p_{j}^{2}+p_{i} p_{j}+2 p_{i}-1=0
$$

Equation (4) and (5) is shown in graph chart as Fig. 5 and Fig. 6, where $p_{i}$ and $p_{j}$ are the minimum and maximum voltage sagging factors respectively, "case 1 " is the case of $p_{j}=1$ in which one of the three-phase voltage is normal, "case 2 " is the case of $p_{i}=p_{j}=p_{k}$ in which the voltage sag is symmetrical. The up-left shadowed area is not valid because $p_{i} \leqq p_{j}$. The "case 3" in Fig. 6 is the characteristics for the original scheme shown in Fig. $1^{(4)}$.

Fig. 5 and Fig. 6 shows following characteristics.

1) If at least one of the phase voltage is maintained normal, the minimum sag voltage which can be continuously compensated changes with the filtering factor $q$ as shown in the case 1 . If the DC capacitor is large enough and $q=1$, the minimum sag voltage can be 0 . This means that the compensator can compensate one or two-phase voltage sags down to 0 continuously, 


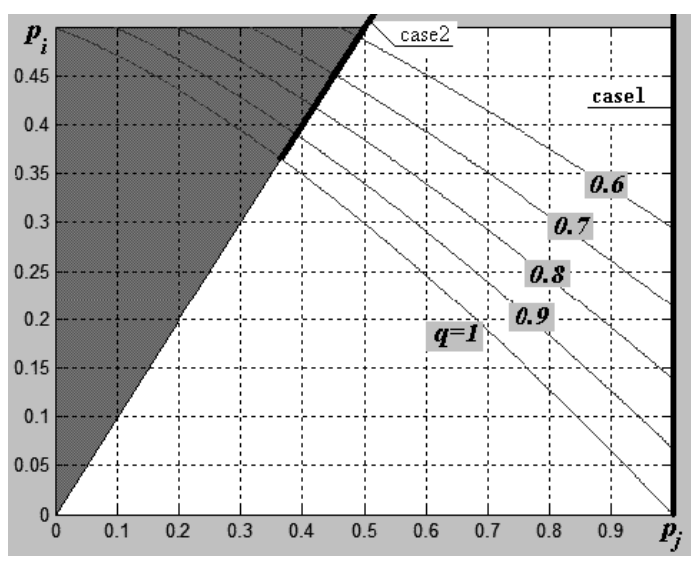

Fig. 5. The graph chart of equation (4)

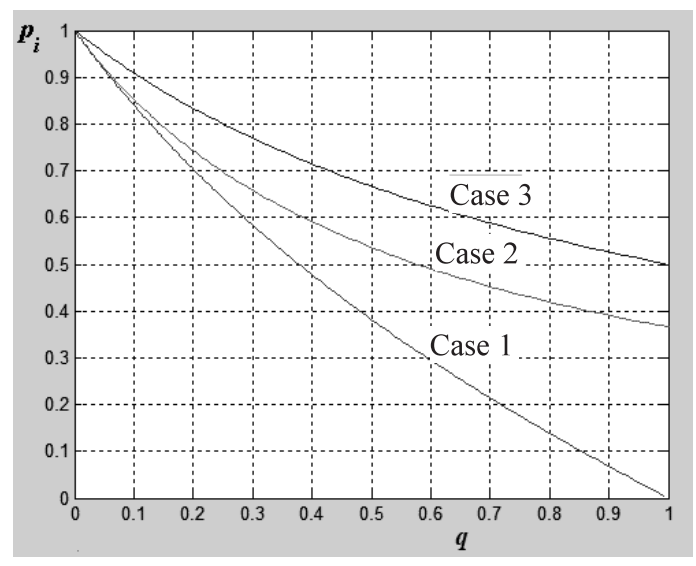

Fig. 6. Relation of $p_{\text {casel } 1}, p_{\text {case } 2}$ and $p_{\text {case } 3}$ via $q$

if one of the phase voltage is maintained normal and $q=1$. The minimum compensated voltage increases with the decrease of filtering factor $q$, which are shown by the thick line of "case 1" in Fig. 5 and "case 1 " in Fig. 6.

2) Symmetrical three-phase voltage sag down to $37 \%$ of the normal voltage can be compensated continuously, if $q=1$. The compensated sag voltage increases with the decrease of filtering factor $q$ as shown by the thick line of "case 2" in Fig. 5 and "case 2" in Fig. 6.

$3)$ Fig. 6 shows that the proposed scheme in this paper can compensate more deeper voltage sags than the original scheme shown in Fig. 1.

3.3 Control Strategy ${ }^{(7)(8)} \quad$ Fig. 7 shows a block diagram of the compensating control system. A tracking control method named as "double $\delta$ modulation" is used. "Double $\delta$ modulation" means the combination of tracking error comparison (amplitude $\delta$ modulation) and carrier timing (time $\delta$ modulating). The "Comparator" with the "Variable threshold", as shown in Fig. 7, achieves the amplitude $\delta$ modulation, its output is a narrow positive pulse sequence named as $R$. The switching “Timer" implements the time $\delta$ modulation, its output is also a narrow positive pulse sequence named as $F$. The "Flip-flop" combines these two modulating action together and then exports SPWM signals of which $F$ synchronizes the falling edges and $R$ decides the rising edges. The "Inverter" controlled by the SPWM signal exports the desired outputs $u_{\mathrm{SPWM}}$. Both the "Comparator" and

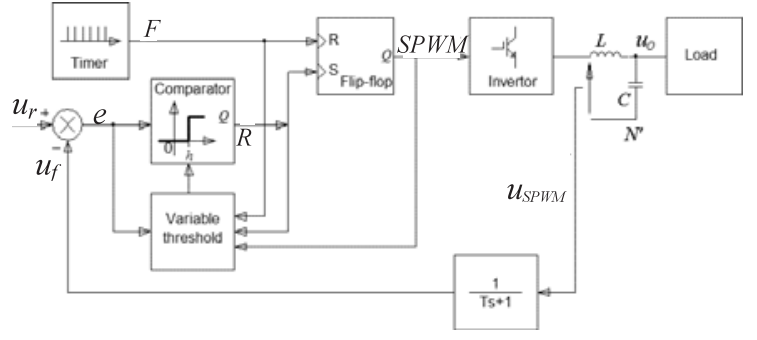

Fig. 7. Block diagram of the control system

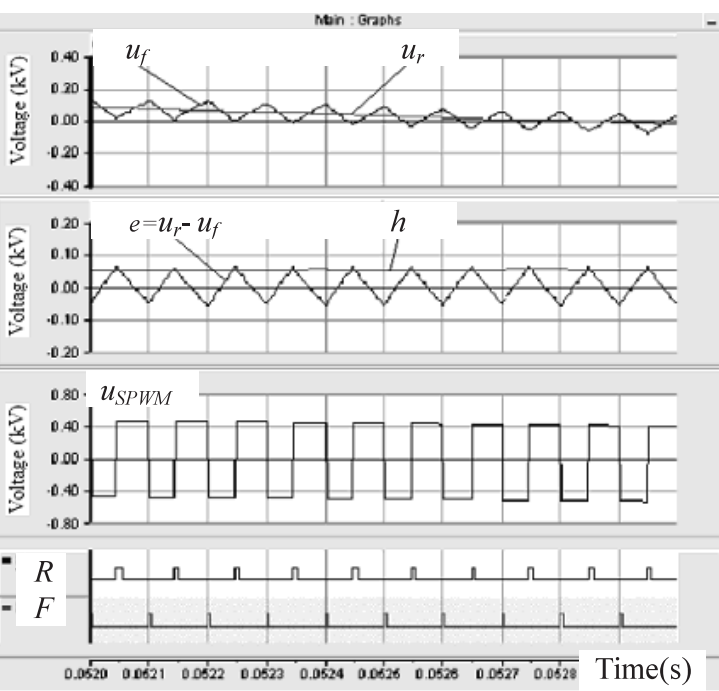

Fig. 8. Example waveforms of the control scheme in Fig. 7

the "Timer" together determine tracking precision. Especially the "Timer" ensures constant switching frequency. The block of "Variable threshold" performs a threshold predicting control, by which the threshold is modified every switching period to ensure the average tracking error to be zero.

Fig. 8 shows the basic operating waveforms that is simulation results of the main circuit topology in Fig. 2 controlled by the control scheme in Fig. 7. The upmost curves are the input reference of rated sine voltage $u_{r}$ and the feedback voltage $u_{f}$, which fundamental part is almost the same of the load voltage, the second set of curves are the tracking error $e=u_{r}-u_{f}$ and the threshold $h$ of the "Comparator", the third one is the output voltage $u_{\text {SPWM }}$ of the inverter, being the voltage between the points of $Y a$ to $N^{\prime}$ in Fig. 2, the undermost curves are the pulse sequences of $R$ and $F$.

3.4 Control of the Bypass Switches The bypass switches are connected in parallel with the inverter only through the inductor $L$ that is shown in Fig. 9. When the incoming source voltages are normal the bypass switches are in operation and the load voltages equal the sources. When voltage sags are detected, the inverters start to operate, so that the load voltages will be restored to normal. At the same time the bypass switches must be shut down to avoid a short circuit.

The bypass switch consists of two anti-parallel thyristors. The current commutation from the thyristors to the inverter depends on the situation of their voltages and currents; if the sourse voltage $e_{2}$ and current $i_{3}$ are at the same sign the commutation will be natural, otherwise the commutation will fail. 


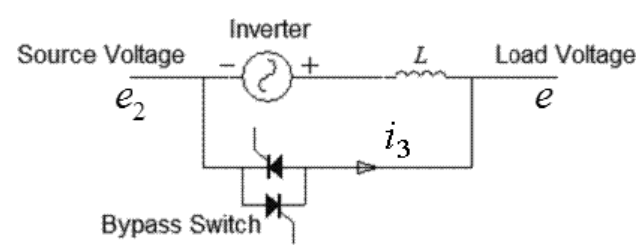

Fig. 9. Circuit topology of the bypass switches

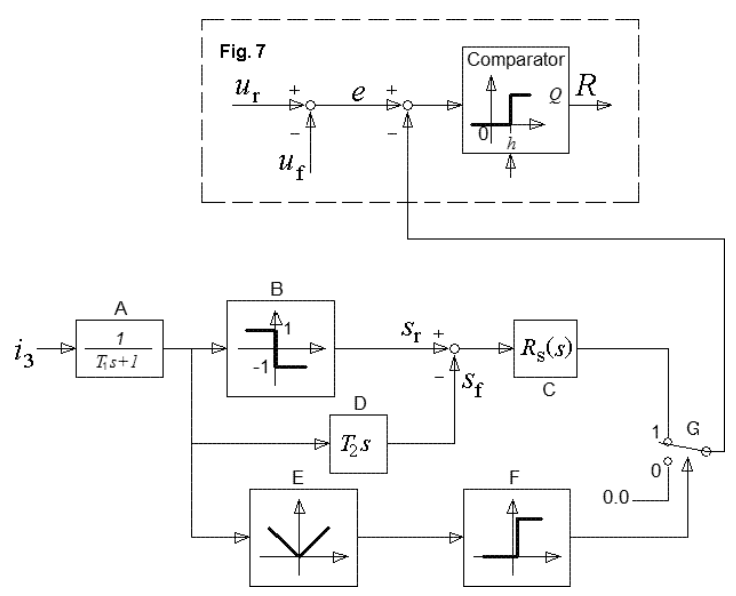

Fig. 10. Block diagram of current slope control for commutation of bypass switches

The conducting thyristor will maintain conduction until its current fall to zero naturally, during which the inverter will be short circuited with inductor $L$. This will result in over current in the inverter and the load voltage cannot be restored in that time interval.

A current slope automatic control method is used in this system. The basic principle is shown in Fig. 10. Block A is a pre-filter of the current $i_{3}$ in bypass switch with a time constant $T_{1}$. Block B is a single input comparator of $i_{3}$ with limited output, where if $i_{3}$ is less than zero it outputs " +1 ", if $i_{3}$ is more than zero it outputs " -1 ". These output is used as a reference input of current slope control. Block $\mathrm{C}$ is the regulator of slope control with the transfer function $R_{\mathrm{S}}(s)$. Block D is a current slope detector with the differential time constant $T_{2}$, those output is used as feedback signal of the current slope tracking control. Block $\mathrm{E}$ and $\mathrm{F}$ are used to detect the zeros state of $i_{3}$; if $i_{3}$ reaches zero the current slope control will be cut off. Block $\mathrm{G}$ is a slection switch.

Fig. 11 shows a set of operating waveforms; the upper one is the currents in bypass switch, and the under one is the load voltages. From this figure, voltage sags occur from $0.04 \mathrm{~s}$, before which the supply voltages are normal. At the begining of the voltage sags, the bypass currets are $i_{a 3}=-14 \mathrm{~A}, i_{b 3}=$ $8 \mathrm{~A}, i_{c 3}=6 \mathrm{~A}$, the invertors start to operate under the control of the current slope controller in Fig. 10. Then, these currents decrease straight to zero by a designed slope of $10 \mathrm{~A} / \mathrm{ms}$. After a corresponding time interval, about $1.4 \mathrm{~ms}, 0.8 \mathrm{~ms}$, and $0.6 \mathrm{~ms}$, respectively, the current reaches zero, which makes the bypass switch turn off. The block G switches to "0" when block F detect the zero current, then the tracking controller as shown in Fig. 7 makes the output load voltage maintain normal.

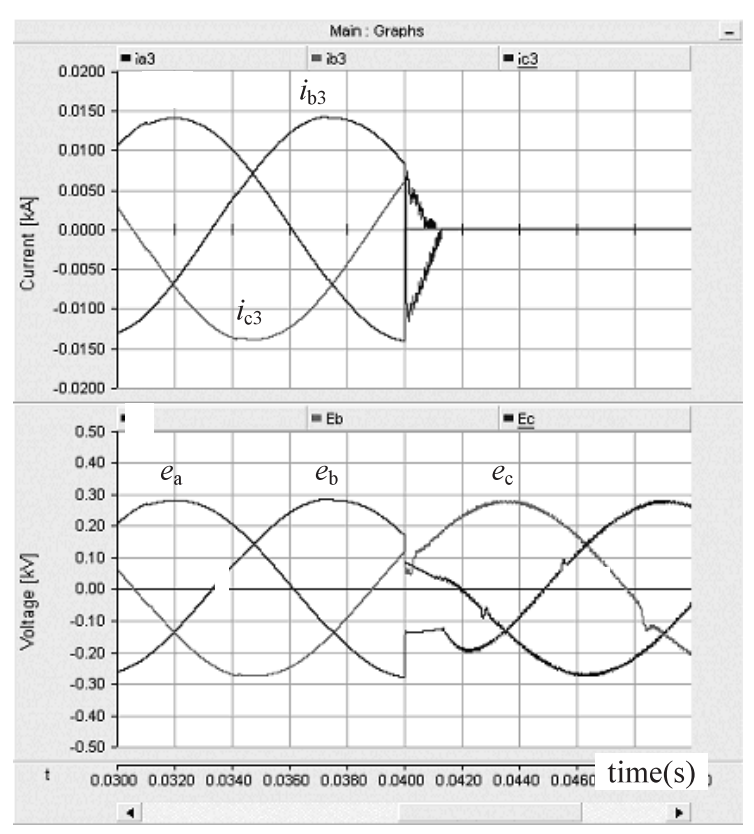

Fig. 11. Simulation result of the commutation by current slope control

\section{System Simulation Study}

4.1 Parameters Design For the circuit topology of voltage sag compensation in Fig. 2 the final controlled outputs must be the load voltages $\left(e_{\mathrm{a}}, e_{\mathrm{b}}\right.$, and $\left.e_{\mathrm{c}}\right)$. The output filters in each phase that consists of $L$ and $C$ is generally necessary, but it has a resonance property. This brings two problems if the voltage in filter capacitor $C$ is directly used as the feedback variable.

First one comes from the larger phase delay, which will make the fast tracking difficult. Second one is the resonance property itself. The damping factor of $L C$ resonance is dependent with the load. When load consists of $L$ and $R$, which is one of general situations, the total damping factor may become very low. It will make the output un-stable, because the SPWM tracing control will produce plenty of harmonics even though the switching frequency maintain constant. For nonlinear loads, the typical condition is power electronic rectifiers in which the load current will be discontinuous; during the interval of zero load current the damping factor will be approximately zero. Even for an R load the damping factor will be lower if the load is very light. In this paper only the first problem is solved. In order to prevent instability from the larger phase delay of the LC filter, a simple first-degree inertial filter is used to produce the tracking feedback signal as shown in Fig. 7.

The system parameters are as followings, power source frequency $f_{\mathrm{s}}=60 \mathrm{~Hz}$, power source line-to-line voltages $U_{\mathrm{s}}=200 \mathrm{Vrms}$, carrier frequency (i.e. the frequency of the timer in the "double $\delta$ modulation") of the SPWM inverter $f_{\mathrm{c}}=10 \mathrm{kHz}$, rating capacity $3 \mathrm{kVA}$ of total three phases, and the capacitors in the inverters $1000 \mu \mathrm{F}$, which can store only $90 \mathrm{~J}$ energy for each phase at the DC capacitor voltage is $300 \mathrm{~V}$.

As for the $L C$ filter, its parameters follow two principals; at first the natural resonant frequency of LC should be in about 


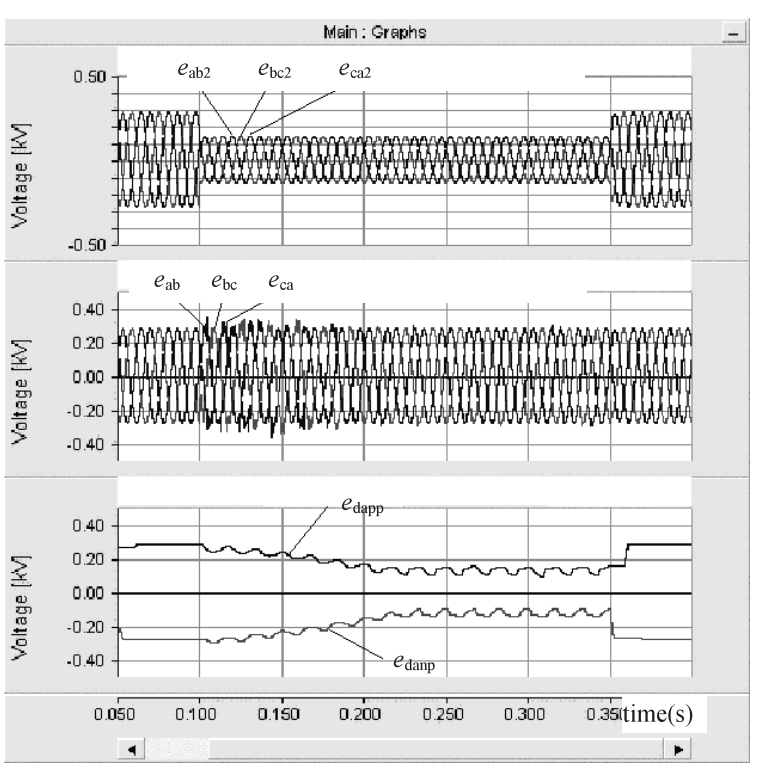

Fig. 12. System simulation result in symmetrical sags down to $44 \%$ residual

the geometric mean of $f_{\mathrm{s}}$ and $f_{\mathrm{c}}$. Secondly the damping factor should be large enough to ensure normal operation. Choosing $L=10 \mathrm{mH}$ and $C=3.3 \mu \mathrm{F}$ takes natural resonant frequency $876 \mathrm{~Hz}$ and a unit damping factor at $1 \mathrm{~kW}$ resistive load for each phase, that is, star connected resistor with $13.5 \mathrm{Ohm}$.

In Fig. 10, designed commutation slope is $10 \mathrm{~A} / \mathrm{ms}$, which corresponds a differential time constant $T_{2}=0.1 \mathrm{~ms}$ in the case of reference input $S_{r}=1$. The pre-filter time constant in block A is tiwce the carrier period, that is $T_{1}=0.2 \mathrm{~ms}$. Finally, let the trasfer function in block $\mathrm{C} R_{\mathrm{S}}(\mathrm{s})=\mathrm{K} / \mathrm{s}$ with $\mathrm{K}=1500$, which makes the closed loop control system of current slope stable.

4.2 Simulation Results The simulation results are obtained by using PSCAD, a visible design environment for power system studies.

Fig. 12 is a system simulation result of the topology in Fig. 2, in which source voltages symmetrically sag down to $44 \%$ residual. Fig. 13 is for the situation of two phase-toneutral voltages sag to $10 \%$ and other one maintaining normal, in other words, two line-to-line voltages sag to $60.8 \%$ and other one sags to $10 \%$ as shown in Fig. 14. In the simulation the loads are star connected resistors of $13.5 \mathrm{Ohm}$, which is the most serious load from the point of required active power for the compensation.

In both of Fig. 12 and Fig. 13, the upper waveforms, $e_{\mathrm{ab} 2}$, $e_{\mathrm{bc} 2}, e_{\mathrm{ca} 2}$, are the sagged incoming source side line-to-line voltages, the middle waveforms, $e_{\mathrm{ab}}, e_{\mathrm{bc}}, e_{\mathrm{ca}}$, are the load side line-to-line voltages after compensation, and the lower waveforms, $e_{\text {dapp }}$ and $e_{\text {danp }}$, defined as same as in Fig. 3(c), are the DC bus voltages of the inverter in phase-A.

From the figures we can see the excellent properties for voltage sag compensation. Only applying small capacitors the proposed compensators can restore symmetrical voltage sags of deeper than $50 \%$, or any two-phase voltage sag down almost to zero. Especially the compensating time is not limited. This can be seen from the DC bus voltages of the inverters as shown in the lower figures of Fig. 12 and Fig. 13. In the time intervals from $0.1 \mathrm{~s}$ to $0.23 \mathrm{~s}$ in Fig. 12 or to $0.18 \mathrm{~s}$ in

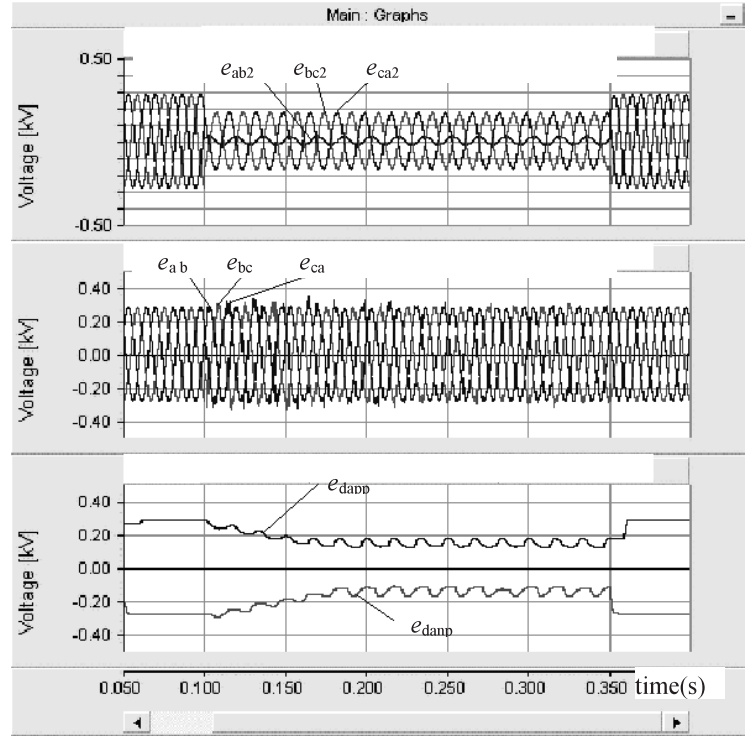

Fig. 13. Simulation of two phases sag to $10 \%$ and other one maintaining normal

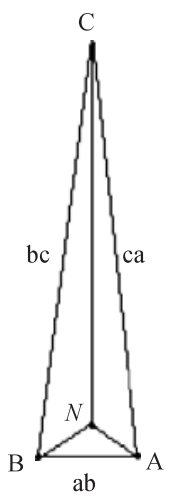

Fig. 14. Phasor diagram during asymmetrical voltage sag

Fig. 13 the inverters compensate the missing voltages by consuming the energy stored in the capacitors, after that time the residual line-to-line voltages begin to continuously charge the capacitors, and maintain the DC bus voltages in dynamical balance which can keep the load voltages in normal.

\section{Conclusion}

A novel series type voltage sag compensator has been proposed, which have three outstanding advantages. Transformer is not used; the large energy storage devices are not necessary; and the compensating time interval is not limited. Theoretical analysis indicate that the proposed scheme can compensate symmetrical three-phase voltage sags down to $37 \%$, or asymmetrical one or two-phase voltage sags down to zero if at least one phase is in normal and the DC bus voltage is smooth enough. Aiming at the bypass switches commutation in this proposed system a so-called "current slope control" method has also been presented. All of the above points has been validated by simulation result. System simulation results for symmetrical three-phase voltage sag down to $44 \%$ and asymmetrical two-phase voltage sag down to $10 \%$ with another phase being in normal were carried out, and the compensating performances were demonstrated. 
Although fundamental characteristics of the proposed topology have been shown, there are several topics need to be studied further, including how the source side impedance effects the compensating property, how to control the compensating system with various type loads, especially for nonlinear rectifying load, and experiment study in detail.

(Manuscript received April 19, 2006,

revised March 12, 2007)

\section{References}

( 1 ) D. Divan, B. Brumsickle, and S. Verrett: "Power disturbances and power electronics equipment - a major cause of unscheduled downtime in large industrial plants", The international power electronics conference, IPECNiigata, Japan, pp.717-723 (2005)

( 2 ) M.F. McGranaghan, D.R. Mueller, and M.J. Samotyj: "Voltage sags in industrial systems", IEEE Trans. IA, Vol.29, pp.397-403 (1993)

( 3 ) P.-T. Cheng, C.-C. Huang, C.-C. Pan, and S. Bhattacharya: "Design and implementation of a series voltage sag compensator under practical utility conditions", IEEE Trans. IA, Vol.39, pp.844-853 (2003)

( 4 ) E.C. Aeloiza, P.N. Enjeti, L.A. Moran, O.C. Montero-Hernandez, and S. Kim: "Analysis and design of a new voltage sag compensator for critical loads in electrical power distribution systems", IEEE Trans. IA, Vol.39, pp.1143-1150 (2003)

( 5 ) W.E. Brumsickle, R.S. Schneider, G.A. Luckjiff, D.M. Divan, and M.F. Mc Granaghan, "Dynamic sag correctors: cost-effective industrial power line conditioning", IEEE Trans. IA, Vol.37, pp.212-217 (2001)

( 6 ) A. Bhadkamkar, A. Bendre, R. Schneider, W. Kranz, and D. Divan: "Application of zig-zag transformers in a three-wire three-phase dynamic sag corrector system", Power Electronics Specialist, IEEE 34th Annual Conference on, PESC'03, Vol.3, 15-19, pp.1260-1265 (2003)
( 7 ) Z. Chen, J. Ren, H. Mao, and Z. Wang: "A Novel Method of 'Double delta Modulation' for Current Tracing Control”, Power System Technology, Vol.29, No.12, pp.62-65 (2005)

( 8 ) Z. Chen, T. Ise, J. Ren, H. Mao, and Z. Wang: "A Novel Method of Double Delta Modulation on Tracking Control of PWM Converters", Proceedings of the CSEE, Vol.26, pp.52-58 (2006)

Zenglu Chen (Non-member) received the B.S. degree from South-

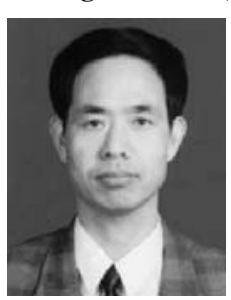
east University, China in 1981 and M.S. degree from Xi' an Jiaotong University, China in 1984, and is currently a professor of Xi'an Polytechnic University, China. He was a foreign researcher of the Electrical Engineering Department, Osaka University, from Oct. 25, 2004 to Apr. 25, 2005. His research interests are power electronics in general, specially multiple PWM inverters, Tracking control of PWM inverters and voltage sag compensation in power systems.

Toshifumi Ise (Member) received the Doctor of Engineering de-

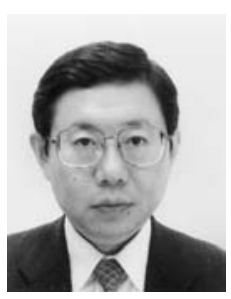
gree in electrical engineering from Osaka University, Japan in 1986. Currently, he is the professor of Division of Electrical, Electronic and Information Engineering at Graduate School of Engineering, Osaka University. His research interests are in the areas of power electronics and applied superconductivity including power quality issues such as voltage sag compensaor, superconducting magnetic energy storage (SMES) and new distribution systems including many distributed generations. He is a member of the Institute of Electrical Engineers of Japan, and IEEE. 